\title{
Endophytic fungi from mangrove inhibit lung cancer cell growth and angiogenesis in vitro
}

\author{
XIN LIU ${ }^{1,2^{*}}$, XIN WU $^{1 *}$, YUEFAN MA ${ }^{1,2}$, WENZHANG ZHANG ${ }^{2}$, LIANG HU $^{2}$, \\ XIAOWEI FENG ${ }^{2}$, XIANGYONG $\mathrm{LI}^{2,3}$ and XUDONG TANG ${ }^{1-3}$ \\ ${ }^{1}$ Guangdong Key Laboratory for Research and Development of Natural Drugs, ${ }^{2}$ Institute of Biochemistry and \\ Molecular Biology, and ${ }^{3}$ Guangdong Provincial Key Laboratory of Medical Molecular Diagnostics, \\ Guangdong Medical University, Xiashan, Zhanjiang, Guangdong 524023, P.R. China
}

Received July 1, 2016; Accepted January 4, 2016

DOI: $10.3892 /$ or.2017.5366

\begin{abstract}
The secondary metabolites of mangrove-derived endophytic fungi contain multiple substances with novel structures and biological activities. In the present study, three types of mangrove plants, namely Kandelia candel, Rhizophora stylosa and Rhizophoraceae from Zhanjiang region including the leaves, roots and stems were collected, and endophytic fungi were isolated, purified and identified from these mangrove plants. MTT assay was used to observe the effects of the isolated endophytic fungi on the growth of A549 and NCI-H460 lung cancer cells. The effect of the endophytic fungi on lung cancer angiogenesis in vitro induced by the HPV-16 E7 oncoprotein was observed. Our results showed that 28 strains of endophytic fungi were isolated, purified and identified from the three types of mangrove plants. Ten strains of endophytic fungi significantly suppressed the growth of A549 and NCI-H460 cells. The average inhibitory rates in the A549 cells were 64.4, 59.5, 81.9, 43.9, 58.3, 56.2, 48.3, 42.4, 93.0 and $49.7 \%$, respectively. The average inhibitory rates in the NCI-H460 cells were 41.2, 49.3, 82.7, 40.7, 53.9, 52.6, 56.8, $64.3,91.0$ and $45.6 \%$, respectively. Particularly, three strains of endophytic fungi markedly inhibited HPV-16 E7 oncoprotein-induced lung cancer angiogenesis in vitro. These findings contribute to the further screening of potential chemotherapeutic agents from mangrove-derived endophytic fungi.
\end{abstract}

Correspondence to: Professor Xudong Tang, Guangdong Key Laboratory for Research and Development of Natural Drugs, Guangdong Medical University, 2 Wenming Donglu, Xiashan, Zhanjiang, Guangdong 524023, P.R. China

E-mail: tangxudong2599@126.com; txd@gdmu.edu.cn

${ }^{*}$ Contributed equally

Key words: mangrove, endophytic fungi, lung cancer, cell growth, angiogenesis

\section{Introduction}

In 1904, the first strain of endophytic fungus was discovered. Since that date, more and more endophytic fungi have been isolated from different natural plants including mangroves (1-5). Research has demonstrated that the secondary metabolites from endophytic fungi contain multiple bioactive compounds with novel structures (1-3). The advantages of endophytic fungi include their short culture cycle, mild conditions for growth, little exposure to environmental pollution and easy industrialization. Thus, these fungi can facilitate the development of traditional pharmaceutical agents. Therefore, the identification of novel natural drugs from endophytic fungi living in different environments and ecosystems offers numerous opportunities.

Mangroves live in high saline and humid environments. Thus, numerous bioactive compounds can be generated under these environmental conditions $(4,5)$. A large number of bioactive compounds have been isolated from endophytic fungi of mangroves, such as, flavonoids, alkaloids, terpenes, quinones, cyclic peptide compounds andfatty acids. Recently, an increased number of novel bioactive compounds have been obtained from mangrove-derived endophytic fungi, such as, novel cyclohexenone, cyclopentenone and xanthone derivatives (6), polyketides (nectriacids A-C and 12-epicitreoisocoumarinol) (7), 3 -epiarigsugacin $\mathrm{E}(8)$, aspergifuranone and isocoumarin derivatives (9), (R)-3-demethyl purpurester A (9), aromatic butyrolactones (flavipesins A and B) (10) and sulfide diketopiperazine derivatives (penicibrocazines A-E) (11). Multiple bioactive compounds from mangrove-derived endophytic fungi have been demonstrated to exhibit inhibitory activities against acetylcholinesterase (AchE) (8), $\alpha$-glucosidase (9), bacteria (10-12) and viruses (13). Particularly, accumulating evidence indicates that various bioactive compounds from mangrove-derived endophytic fungi display antitumor activities (13-18). Furthermore, studies have reported the underlying mechanisms of the antitumor effects of mangrove-derived endophytic fungi (19-24). An anthraquinone compound G503, isolated from the secondary metabolites of the mangrove endophytic fungus Nigrospora sp. (no. 2508), was reported to induce apoptosis in gastric cancer SGC7901 cells through the mitochondrial pathway (19). Xyloketal B, a marine compound 
obtained from the mangrove fungus Xylaria sp. (no. 2508) from the South China Sea, was demonstrated to suppress the proliferation and migration of glioblastoma U251 cells by inhibiting the TRPM7-mediated PI3K/Akt and MEK/ERK signaling pathways (20). The marine anthraquinone derivative SZ-685C, isolated from the secondary metabolites of the mangrove endophytic fungus Halorosellinia sp. (no. 1403), was found to induce apoptosis in primary human non-functioning pituitary adenoma (21), breast cancer (22) and human nasopharyngeal carcinoma (NPC) cells (23), and reverse the adriamycin-resistance in breast cancer cells (24) by the inhibition of the Akt pathway. Taken together, these findings indicate that the bioactive compounds from mangrove-derived endophytic fungi can inhibit cancer cell growth via the induction of apoptosis and the inhibition of the Akt signaling pathway. However, the effect of mangrove-derived endophytic fungi on cancer angiogenesis has not yet been reported.

Angiogenesis, the development of new microvascular networks, is required for cancer invasion and metastasis and plays a key role in controlling the development and progression of a variety of cancers (25). The inhibition of cancer angiogenesis can suppress the development and progression of cancers. Therefore, the screening of angiogenic inhibitors from mangrove-derived endophytic fungi is extremely important for identifying new chemotherapeutic drugs for the prevention and treatment of cancers. There are abundant resources of mangroves in Zhanjiang. Therefore, the present study was to isolate, purify and identify endophytic fungi from Zhanjiang mangroves and explore their effects on the growth and angiogenesis of lung cancer cells.

In the present study, we isolated, purified and identified 28 strains of endophytic fungi from three types of mangrove plants, namely Kandelia candel, Rhizophora stylosa and Rhizophoraceae, and 10 strains of endophytic fungi significantly suppressed the growth of lung cancer cell lines, A549 and NCI-H460. Furthermore, to the best of our knowledge, we demonstrated for the first time, that three strains of endophytic fungi markedly inhibited lung cancer angiogenesis in vitro.

\section{Materials and methods}

Reagents. Glucose was purchased from the Tianjin Fuchen Chemical Reagents Factory (Tianjin, China). Potato dextrose agar (PDA) was obtained from Hangzhou Microbial Reagent Co., Ltd. (Hangzhou, China). Tryptone and yeast extract reagents were purchased from Oxoid Ltd. (Basingstoke, Hampshire,UK). Transfection reagent (Lipofectamine ${ }^{\mathrm{TM}}$ 2000) was obtained from Invitrogen Corp. (Carlsbad, CA, USA). In vitro angiogenesis assay kit (ECM625) was obtained from Millipore (Temecula, CA, USA). Fungus genomic DNA extraction kit was purchased from Bioer Technology Co., Ltd. (Tokyo, Japan). MTT kit was purchased from Beyotime Biotechnology (Shanghai, China).

Collection of mangrove plants. The healthy leaves, roots and stems of mangroves (Kandelia candel, Rhizophora stylosa and Rhizophoraceae) were collected from Haibin Park and Gaoqiao National Mangrove Nature Reserve (Zhanjiang, Guangdong, China). The collected leaves, roots and stems of the mangroves were washed for $2 \mathrm{~h}$ under running tap water and were cut into $\sim 0.5 \times 0.5 \mathrm{~cm}$ pieces within $72 \mathrm{~h}$ after collection. The surface of the fragments was sterilized by sequential immersion in $75 \%$ ethanol $\left(\mathrm{C}_{2} \mathrm{H}_{5} \mathrm{OH}\right)$ for $45 \mathrm{sec}$ and $5 \%$ sodium hypochlorite $(\mathrm{NaClO})$ for different times (leaves for $3 \mathrm{~min}$, roots for $10 \mathrm{~min}$ and stems for $5 \mathrm{~min}$ ), followed by washing four to five times with sterile distilled water.

Isolation, purification and culture of the endophytic fungi. The sterilized fragments of mangroves were dried under sterile conditions. The dried fragments were cultured in plates with PDA medium (potato extract $10.0 \mathrm{~g} / 1$, glucose $20.0 \mathrm{~g} / \mathrm{l}$, agar $13.0 \mathrm{~g} / \mathrm{l}$ and chloramphenicol $0.1 \mathrm{~g} / \mathrm{l}$ ) at $28^{\circ} \mathrm{C}$, and the growth of the endophytic fungal colonies from the mangrove fragments was monitored every day. The fungal colonies which grew out from the mangrove fragments were isolated and transferred to other plates with PDA medium for purification. The purified endophytic fungal colonies were photographed.

Next, the purified endophytic fungal colonies were fermented at $28^{\circ} \mathrm{C}$ in glucose peptone yeast (GPY) extract broth (tryptone $2.0 \mathrm{~g} / 1$, yeast extract $1.0 \mathrm{~g} / 1$, glucose $10.0 \mathrm{~g} / 1$, and sea salt $20.0 \mathrm{~g} / \mathrm{l})$ in a shaking incubator $(160 \mathrm{rpm})$ at $28^{\circ} \mathrm{C}$ in the dark. Seven days later, fungus culture media were filtered using nylon nets to separate the mycelia and the culture broth. Mycelia were identified by molecular analysis of the internal transcribed spacer (ITS) of the genomic DNA. The culture broths were sterilized by filtration through a $0.22-\mu \mathrm{m}$ Millipore filter, and the filtrates were used for MTT and in vitro angiogenesis assays.

Molecular identification of the endophytic fungi. Genomic DNA was extracted from the separated mycelia according to the manufacturer's instructions (Bioer Technology Co., Ltd.). $18 \mathrm{~S}$ rDNA fragments were amplified by PCR methods with universal primers. PCR primers used were: 5'-TCCGTA GGTGAACCTGCGG-3' (forward) and 5'-TCCTCCGCT TATTGATATGC-3' (reverse) (GenBank, NM_006486.2). The primers were synthesized by Sangon Biotech Co., Ltd. (Shanghai, China). The thermocycling conditions were as follows: $94^{\circ} \mathrm{C}$ for $5 \mathrm{~min}$, followed by 35 cycles at $94^{\circ} \mathrm{C}$ for $45 \mathrm{sec}, 55^{\circ} \mathrm{C}$ for $45 \mathrm{sec}$, and $72^{\circ} \mathrm{C}$ for $60 \mathrm{sec}$, finally $72^{\circ} \mathrm{C}$ for $7 \mathrm{~min}$. The PCR products were detected by $1.5 \%$ agarose gel electrophoresis and DNA sequencing. The results of agarose gel electrophoresis were photographed. DNA sequences were analyzed by Sangon Biotech Co., Ltd. 18S rDNA fragment sequences of the isolated endophytic fungi were compared with those in the GenBank database using BLAST at the National Center for Biotechnology Information (NCBI; Bethesda, MD, USA), and endophytic fungi were classified by morphologic traits and molecular identification. The phylogenetic trees were constructed by Mega 5.0 software.

Cell culture. Human lung adenocarcinoma cell line A549 and human umbilical vein endothelial cells (HUVECs) were purchased from the American Type Culture Collection (ATCC; Rockville, MD, USA). Human lung cancer cell line NCI-H460 was obtained from the Chinese Academy of Sciences Cell Bank of Type Culture Collection (Shanghai, China). A549 and NCI-H460 cells were cultured in RPMI-1640 medium containing $10 \%$ fetal bovine serum (FBS). HUVEC cells were 

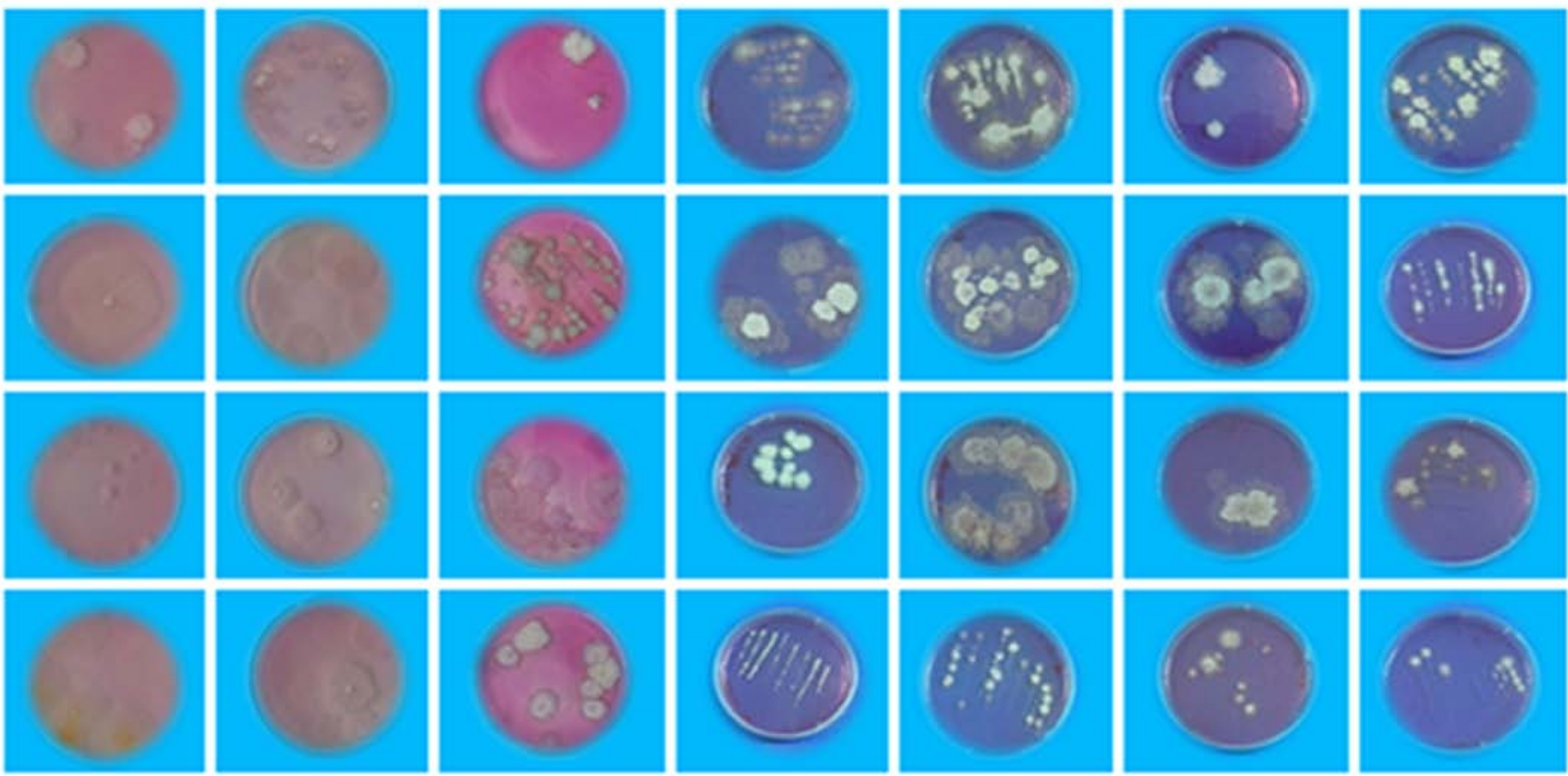

Figure 1. Twenty-eight different strains of endophytic fungi were isolated from mangroves in Zhanjiang region (magnification, x200).
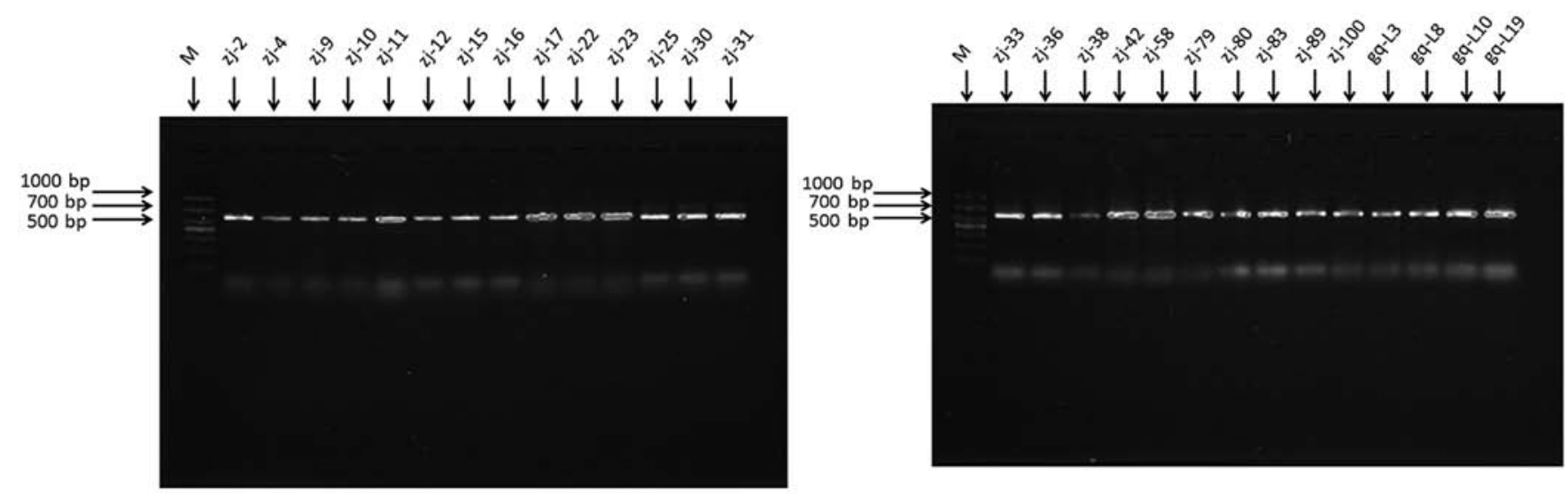

Figure 2. Agarose gel electrophoresis results of $18 \mathrm{~S}$ rDNA of the endophytic fungi isolated from the mangroves. The $18 \mathrm{~S}$ rDNAs extracted from 28 strains of mangrove-derived endophytic fungi were amplified by PCR. The PCR products were detected by $1.5 \%$ agarose gel electrophoresis.

grown in DEME media containing $10 \%$ FBS. All cells were maintained in a $5 \% \mathrm{CO}_{2}$ incubator at $37^{\circ} \mathrm{C}$.

Transient transfection. Transient transfection was carried out according to a previously described method $(26,27)$. The plasmid (p-EGFP-N1-HPV-16 E7), constructed by our laboratory, was transiently transfected into A549 and NCI-H460 cells using Lipofectamine ${ }^{\mathrm{TM}} 2000$ according to the manufacturer's instructions, wherein transfection with the empty vector (p-EGFP-N1) served as the negative controls. The cells exposed to transfection reagent alone served as mock transfection controls. The transfection efficiency was evaluated by observing green fluorescence under a fluorescence microscope, and the expression of HPV-16 E7 oncoprotein was confirmed in our previous studies $(26,27)$.
MTT assay. The MTT [3-(4,5-dimethylthiazol-2-yl)2,5-diphenyltetrazolium bromide) assay was performed to determine the effects of endophytic fungi on the growth of A549 and H460 cells. A cell suspension was added to 96-well plates at the density of $5 \times 10^{4} / \mathrm{ml}(100 \mu \mathrm{l} /$ well $)$, and cultured in a $\mathrm{CO}_{2}$ incubator overnight at $37^{\circ} \mathrm{C}$. Afterwards, the culture medium was replaced with fresh medium, and $20 \mu \mathrm{l}$ culture broth of the different endophytic fungi was added into the wells for culture at $37^{\circ} \mathrm{C}$ for $72 \mathrm{~h}$. Each culture broth of the endophytic fungi was repeated four times. Seventy-two hours later, the supernatant was removed, followed by addition of $20 \mu \mathrm{l}$ MTT [5 mg/ml in phosphate-buffered saline (PBS)] into each well, and the cells were incubated for an additional $4 \mathrm{~h}$. After removing the supernatant, $150 \mu$ l dimethyl sulfoxide (DMSO) was added into each well. The cells were incubated for 


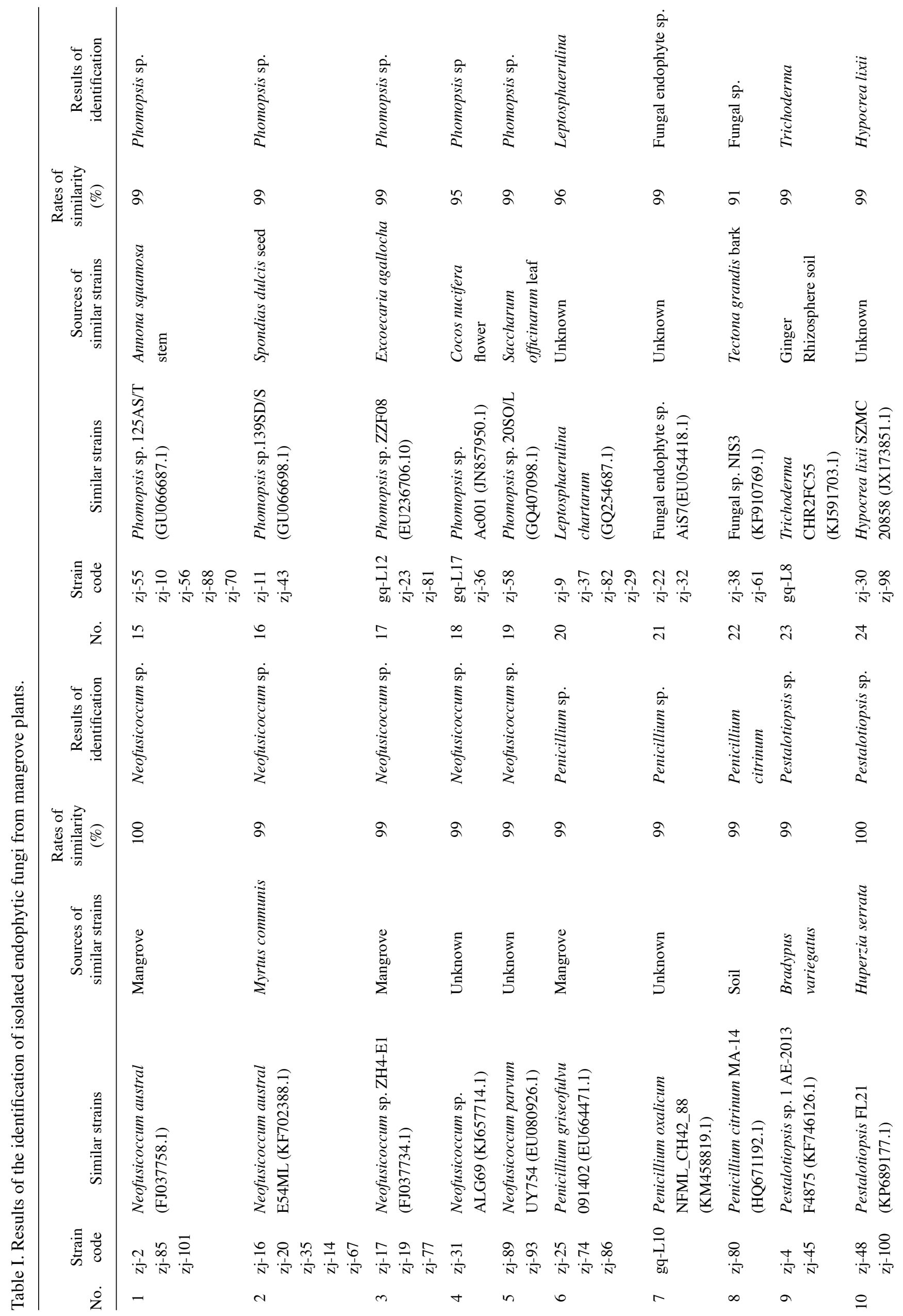


$10 \mathrm{~min}$ at room temperature in order to fully dissolve the formed crystals. Absorbance values at $595 \mathrm{~nm}$ were measured using a microplate reader and cell viability was calculated.

In vitro angiogenesis assay. An in vitro angiogenesis assay kit (ECM625) was employed to analyze the formation of capillary tube-like structures according to the manufacturer's instructions. Briefly, HUVECs were seeded at a density of $5 \times 10^{3}$ cells/well onto the surface of 96-well cell culture plates pre-coated with polymerized ECMatrix ${ }^{\mathrm{TM}}$. Subsequently, the conditioned media, derived from HPV-16 E7-transfected A549 or NCI-H460 cells treated with $20 \mu \mathrm{l}$ culture broth of the different endophytic fungi, were respectively added into different wells. Tubule formation was observed under a phasecontrast microscope, and Scion image software was used to analyze the total tube length in three random view fields/well, and the average value was calculated. The experiment was repeated in triplicate.

Statistical analysis. The experiment was repeated at least three times. One way ANOVA and LSD were employed for statistical analysis using SPSS 19.0. $\mathrm{P}<0.05$ was considered to indicate a statistically significant result.

\section{Results}

Results of the isolation, purification and identification of the endophyte fungi. Sixty-two strains of endophytic fungi were isolated from three types of mangrove plants (Kandelia candel, Rhizophora stylosa and Rhizophoraceae) in the Zhanjiang region. The number of endophytic fungus strains isolated from Kandelia candel, Rhizophora stylosa and Rhizophoraceae was 26, 20 and 16, respectively. After sequencing, 34 strains of endophytic fungi were found to have the same sequences. After removal of the repeated ones, 28 different strains of endophytic fungi were successfully isolated in the present study (Fig. 1). To further identify the 28 strains of endophytic fungi, the $18 \mathrm{~S}$ rDNA was amplified by PCR. The results from agarose gel electrophoresis of the PCR products are shown in Fig. 2. As shown in Fig. 2, the size of the PCR products was from 500 to $750 \mathrm{bp}$, indicating that the 28 strains belonged to fungi. Compared with the sequences in the GenBank database, 28 different strains of endophytic fungi were successfully identified (Table I). Next, the phylogenetic trees were constructed using Mega 5.0 software. The phylogenetic trees of three types of mangroves, Kandelia candel, Rhizophora stylosa, and Rhizophoraceae, are shown in Figs. 3-5, respectively.

Results of the MTT assay. To assess the antitumor activities of the 28 isolated strains of endophytic fungi, MTT assay was performed to observe the effects of these fungi on the growth of human lung cancer cells, A549 and NCI-H460. The results from the MTT assay are shown in Table II. As shown in Table II, 10 strains of endophytic fungi, including 4 Neofusicoccum sp. strains (zj-2, zj14, zj-17 and zj-67), 4 Phomopsis sp. strains (zj-12, zj-23, zj-36 and $\mathrm{zj}-70), 1$ Leptosphaerulina sp. strain (zj-9) and 1 Penicillium sp. strain (zj-25), significantly inhibited the growth of lung cancer A549 and NCI-H460 cells. The average inhibitory rates of 10 strains 


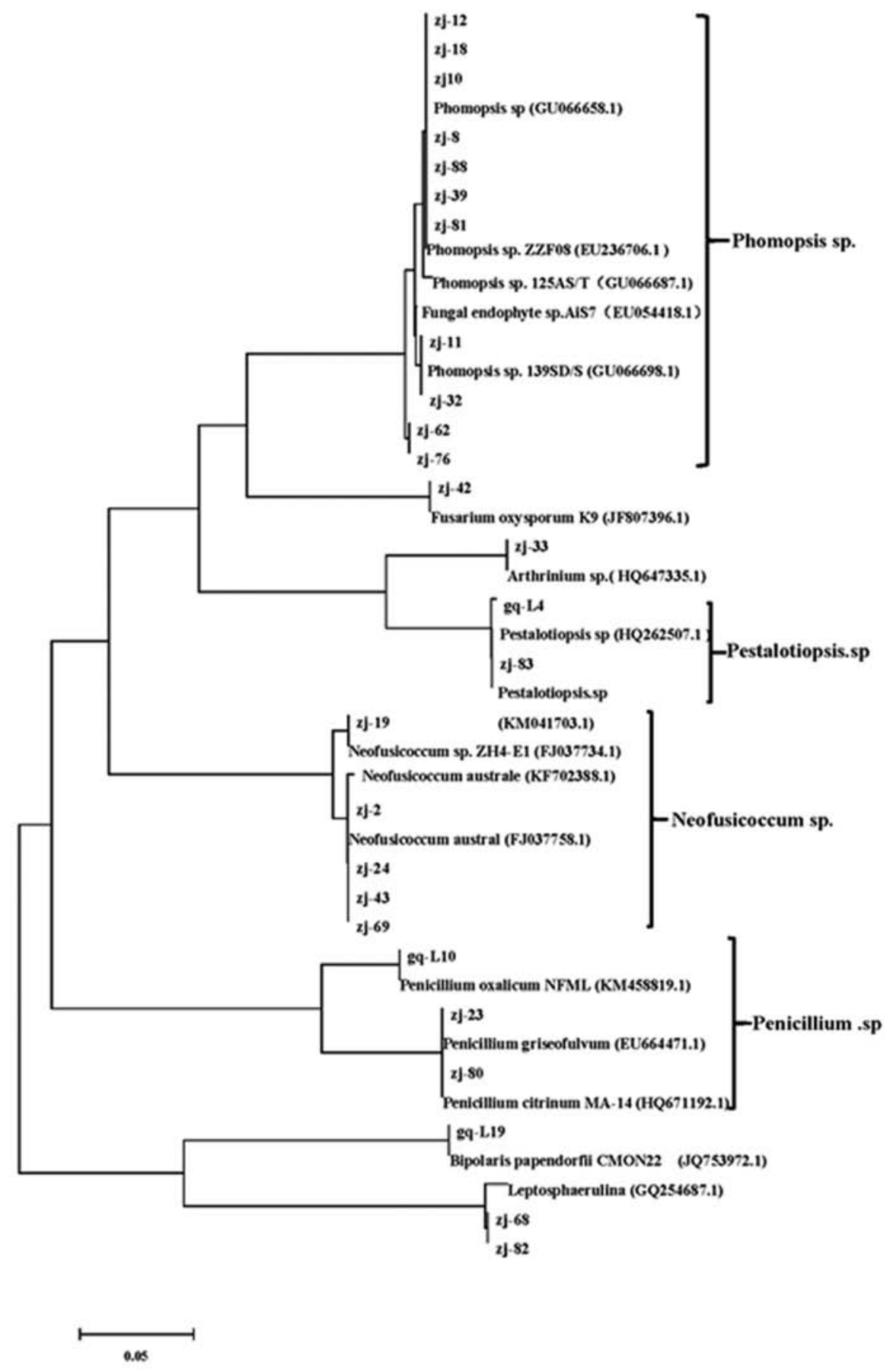

Figure 3. The phylogenetic tree of Kandelia candel. The sequences of endophytic fungi isolated from Kandelia candel were compared with those in the GenBank database using BLAST, followed by the construction of the phylogenetic tree using Mega 5.0 software.

in the A549 cells were $64.4,59.5,81.9,43.9,58.3,56.2,48.3$, $42.4,93.0$ and $49.7 \%$, respectively. The average inhibitory rates of 10 strains in the NCI-H460 cells were 41.2, 49.3, 82.7, 40.7, $53.9,52.6,56.8,64.3 \%, 91.0$ and $45.6 \%$, respectively. The zj-9 and zj-17 strains showed a stronger inhibitory effects on both the A549 and NCI-H460 lung cancer cell lines. Particularly, zj-9 exhibited the strongest growth inhibitory activity in the two lung cancer cell lines.

Results of the in vitro angiogenesis assay. To further explore the underlying mechanism of the antitumor activity of the endophytic fungi, an in vitro angiogenesis assay was performed to observe the effects of endophytic fungi on the inhibition of lung cancer angiogenesis. In our previous studies, we found that human papillomavirus (HPV) type 16 E7 (HPV-16 E7) oncoprotein significantly enhanced lung cancer cell angiogenesis in vitro $(26,27)$. Therefore, in the present study, we established an in vitro angiogenesis model induced by HPV-16 E7 oncoprotein. As shown in Fig. 6, HPV-16 E7 oncoprotein markedly stimulated microtubule formation (Fig. 6, image 2) as compared with the empty vector control (Fig. 6, image 1), which was 


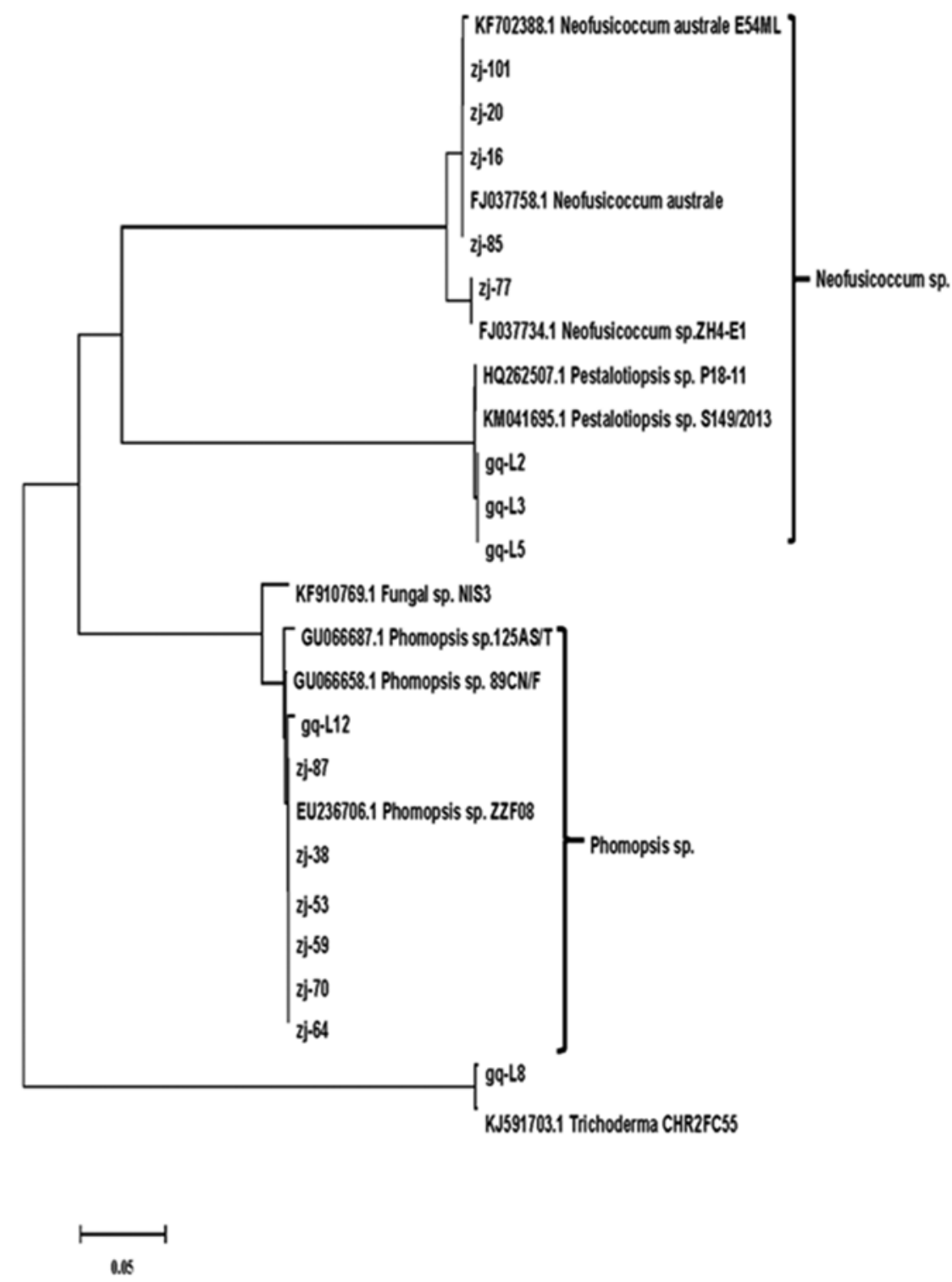

Figure 4. The phylogenetic tree of Rhizophora stylosa. The sequences of endophytic fungi isolated from Rhizophora stylosa were compared with those in the GenBank database using BLAST, followed by the construction of the phylogenetic tree using Mega 5.0 software.

in accordance with our previous studies $(26,27)$, indicating that the model was successfully established. In the present study, we further found that endophytic fungi zj-14 (image 6), zj-17 (image 7) and zj-36 (image 10) markedly inhibited HPV-16 E7-stimulated microtubule formation (Fig. 6; $\mathrm{P}<0.01$ ) in both A549 (Fig. 6A) and NCI-H460 (Fig. 6C) cells, which was further confirmed by total tube length (Fig. 6B and D; $\mathrm{P}<0.01$ ). Additionally, endophytic fungus zj-23 (lane 8) inhibited HPV-16 E7-stimulated microtubule formation in the A549 cells (Fig. 6A and $\mathrm{B} ; \mathrm{P}<0.01$ ) and endophytic fungus zj-12 (lane 5) inhibited HPV-16 E7-stimulated microtubule formation in the NCI-H460 cells (Fig. 6C and D; $\mathrm{P}<0.05$ ).

\section{Discussion}

In the present study, we isolated 26, 20 and 16 strains of endophytic fungi from three types of mangrove plants, Kandelia candel, Rhizophora stylosa and Rhizophoraceae, respectively. There are a variety of endophytic fungi that may be isolated from one type of mangrove plant, but one to three endophytic fungi are dominant. We found that the dominant endophytic fungi of Kandelia candel, Rhizophora stylosa and Rhizophoraceae were Pestalotiopsis sp. (42.3\%), Pestalotiopsis sp. (20\%) and Phomopsis sp. (43.8\%), respectively. Notably, Neofusicoccum sp. (31.3\%) was also found to be a major advantage endophytic fungi isolated from Rhizophoraceae in addition to Phomopsis sp.

A growing body of evidence indicates that multiple bioactive compounds isolated from mangrove-derived endophytic fungi inhibit the growth of cancer cells (15-18). A new sesquiterpene named botryosphaerin $\mathrm{F}$ from the mangrove fungus Aspergillus terreus (no. GX7-3B) was reported to inhibit the growth of human breast cancer MCF-7 and leukemia HL-60 cells with $\mathrm{IC}_{50}$ values of 4.49 and $3.43 \mu \mathrm{M}$, respectively (15). Five highly oxygenated chromones, rhytidchromones A-E, were isolated from the culture broth of a mangrove-derived 


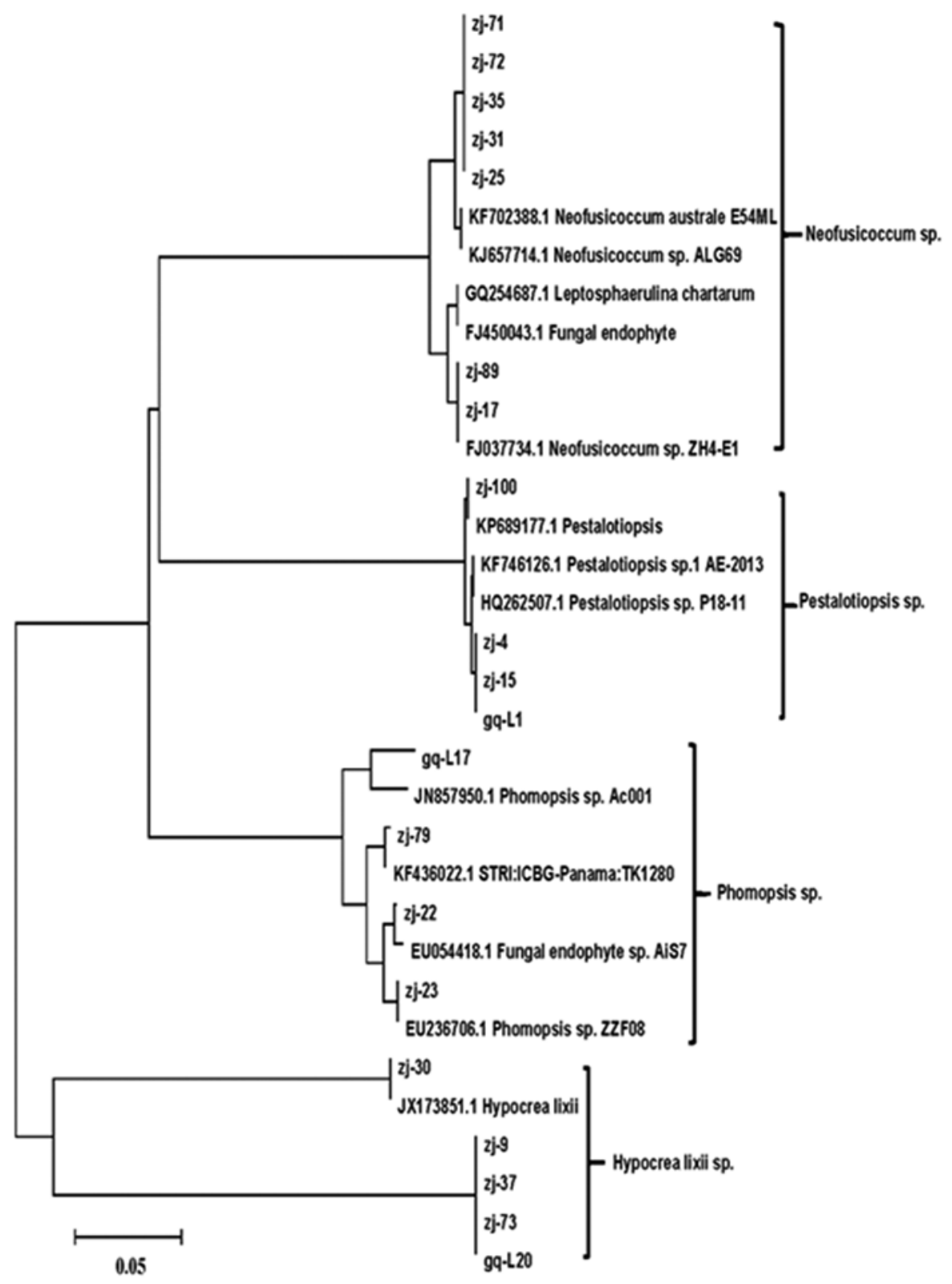

Figure 5. The phylogenetic tree of Rhizophoraceae. The sequences of endophytic fungi isolated from Rhizophoraceae were compared with those in the GenBank database using BLAST, followed by the construction of the phylogenetic tree using Mega 5.0 software.

endophytic fungus, Rhytidhysteron rufulum, and all compounds, except for rhytidchromone D, displayed cytotoxicity against Kato-3 cancer cells with $\mathrm{IC}_{50}$ values ranging from 16.0 to $23.3 \mu \mathrm{M}$, while rhytidchromones $\mathrm{A}$ and $\mathrm{C}$ showed activity against breast cancer MCF-7 cells with $\mathrm{IC}_{50}$ values of 19.3 and $17.7 \mu \mathrm{M}$, respectively (16). Four new lasiodiplodins (1-4) were isolated from a mangrove endophytic fungus, Lasiodiplodia sp. 318\#., and compound 4 exhibited moderate cytotoxic activities against human cancer lines THP1, MDA-MB-435, A549, HepG2 and HCT-116 (17). Two of the three new resveratrol derivatives, namely resveratrodehydes, isolated from the mangrove endophytic fungus Alternaria sp. R6, were found to exhibit cytotoxic activities against human breast cancer cell line MDA-MB-435 and human colon cancer cell line HCT-116s $\left(\mathrm{IC}_{50}<10 \mu \mathrm{M}\right)(18)$. Additionally, Tao et al (28) separated 87 compounds from mangrove endophytic fungus in Southern China, of which $14 \%$ of the compounds had antitumor activity. In the present study, we found that 10 strains, including Neofusicoccum sp. 4 strains (zj-2, zj14, zj-17 and zj-67), Phomopsis sp. 4 strains (zj-12, zj-23, zj-36 and zj-70), Leptosphaerulina sp. 1 strain (zj-9) and Penicillium sp. 1 strain (zj-25), significantly inhibited the growth of the lung cancer cells, A549 and NCI-H460.

Angiogenesis plays a key role in cancer invasion and metastasis. Thus, inhibition of angiogenesis is an effective strategy for cancer prevention $(25,29,30)$. At present, multiple natural compounds have been reported in in vitro and in vivo experiments to inhibit angiogenesis, and most of them from terrestrial plants (29-33). Recently, the screening of marine medicines from the sea and its surroundings has also attracted increased attention. A number of angiogenic inhibitors from marine organisms have been found $(34,35)$. 
Table II. Results from the MTT assay.

\begin{tabular}{|c|c|c|c|c|c|c|c|}
\hline No. & $\begin{array}{l}\text { Strain } \\
\text { code }\end{array}$ & $\begin{array}{c}\text { Average } \\
\text { inhibitory } \\
\text { rates in } \\
\text { A549 cells }(\%)\end{array}$ & $\begin{array}{c}\text { Average } \\
\text { inhibitory } \\
\text { rates in } \\
\text { NCI-H460 cells }(\%)\end{array}$ & No. & $\begin{array}{l}\text { Strain } \\
\text { code }\end{array}$ & $\begin{array}{c}\text { Average } \\
\text { inhibitory } \\
\text { rates in } \\
\text { A549 cells (\%) }\end{array}$ & $\begin{array}{c}\text { Average } \\
\text { inhibitory } \\
\text { rates in } \\
\text { NCI-H460 cells }(\%)\end{array}$ \\
\hline 1 & $\begin{array}{l}\mathrm{zj}-2 \\
\mathrm{zj}-85 \\
\mathrm{zj}-101\end{array}$ & 64.4 & 41.2 & 15 & $\begin{array}{l}z j-55 \\
z j-10 \\
z j-56 \\
z j-88 \\
z j-70\end{array}$ & 9.4 & 0.14 \\
\hline 2 & $\begin{array}{l}z j-16 \\
z j-20 \\
z j-35 \\
z j-14 \\
z j-67\end{array}$ & 56.9 & 14.4 & 16 & $\begin{array}{l}\mathrm{zj}-11 \\
\mathrm{zj}-43\end{array}$ & 18.9 & 10.2 \\
\hline 3 & $\begin{array}{l}\mathrm{zj}-17 \\
\mathrm{zj}-19 \\
\mathrm{zj}-77\end{array}$ & 81.9 & 82.7 & 17 & $\begin{array}{l}\text { gq-L12 } \\
\text { zj-23 } \\
\text { zj-81 }\end{array}$ & 16.0 & 37.2 \\
\hline 4 & $z j-31$ & 43.6 & 13.7 & 18 & $\begin{array}{l}\text { gq-L17 } \\
\text { zj-36 }\end{array}$ & 48.3 & 56.8 \\
\hline 5 & $\begin{array}{l}z j-89 \\
z j-93\end{array}$ & 20.2 & 39.9 & 19 & zj-58 & 16.0 & 39.4 \\
\hline 6 & $\begin{array}{l}\mathrm{zj}-25 \\
\mathrm{zj}-74 \\
\mathrm{zj}-86\end{array}$ & 49.7 & 45.6 & 20 & $\begin{array}{l}z j-9 \\
z j-37 \\
z j-82 \\
z j-29\end{array}$ & 93.0 & 91.0 \\
\hline 7 & gq-L10 & 42.4 & 64.3 & 21 & $\begin{array}{l}\mathrm{zj}-22 \\
\mathrm{zj}-32\end{array}$ & 47.7 & 32.1 \\
\hline 8 & $\mathrm{zj}-80$ & 7.6 & 11.5 & 22 & $\begin{array}{l}z j-38 \\
z j-61\end{array}$ & 37.4 & 36.0 \\
\hline 9 & $\begin{array}{l}z j-4 \\
z j-45\end{array}$ & 39.7 & 54.8 & 23 & gq-L8 & 15.1 & 17.9 \\
\hline 10 & $\begin{array}{l}z j-48 \\
z j-100\end{array}$ & 6.8 & 4.9 & 24 & $\begin{array}{l}\text { zj-30 } \\
\text { zj-98 }\end{array}$ & 64.9 & 7.5 \\
\hline 11 & $\begin{array}{l}\text { gq-L1 } \\
\text { zj-15 }\end{array}$ & 4.6 & 11.7 & 25 & $z j-33$ & 1.7 & 4.1 \\
\hline 12 & $\begin{array}{l}\text { gq-L5 } \\
\text { gq-L3 }\end{array}$ & 15.4 & 37.7 & 26 & gq-L19 & 17.0 & 9.7 \\
\hline 13 & $\begin{array}{l}z j-50 \\
z j-83\end{array}$ & 17.4 & 24.2 & 27 & $\begin{array}{l}z j-42 \\
z j-68\end{array}$ & 13.4 & 17.3 \\
\hline 14 & $\begin{array}{l}z j-39 \\
z j-87 \\
z j-12 \\
z j-64\end{array}$ & 21.4 & 47.7 & 28 & zj-79 & 11.4 & 16.7 \\
\hline
\end{tabular}

Moreover, anti-angiogenic drugs can also be isolated from endophytic fungi (36-38). Altersolanol, isolated from an Alternaria sp. endophytic fungus, was reported to show promising anti-angiogenic activity ex vivo, in vitro and in vivo by the suppression of proliferation, tube formation and migration (36). The phenolic compounds, isolated from an endophytic fungus Coccomyces proteae collected from a Costa Rican rainforest, were reported to have anti-angiogenic 

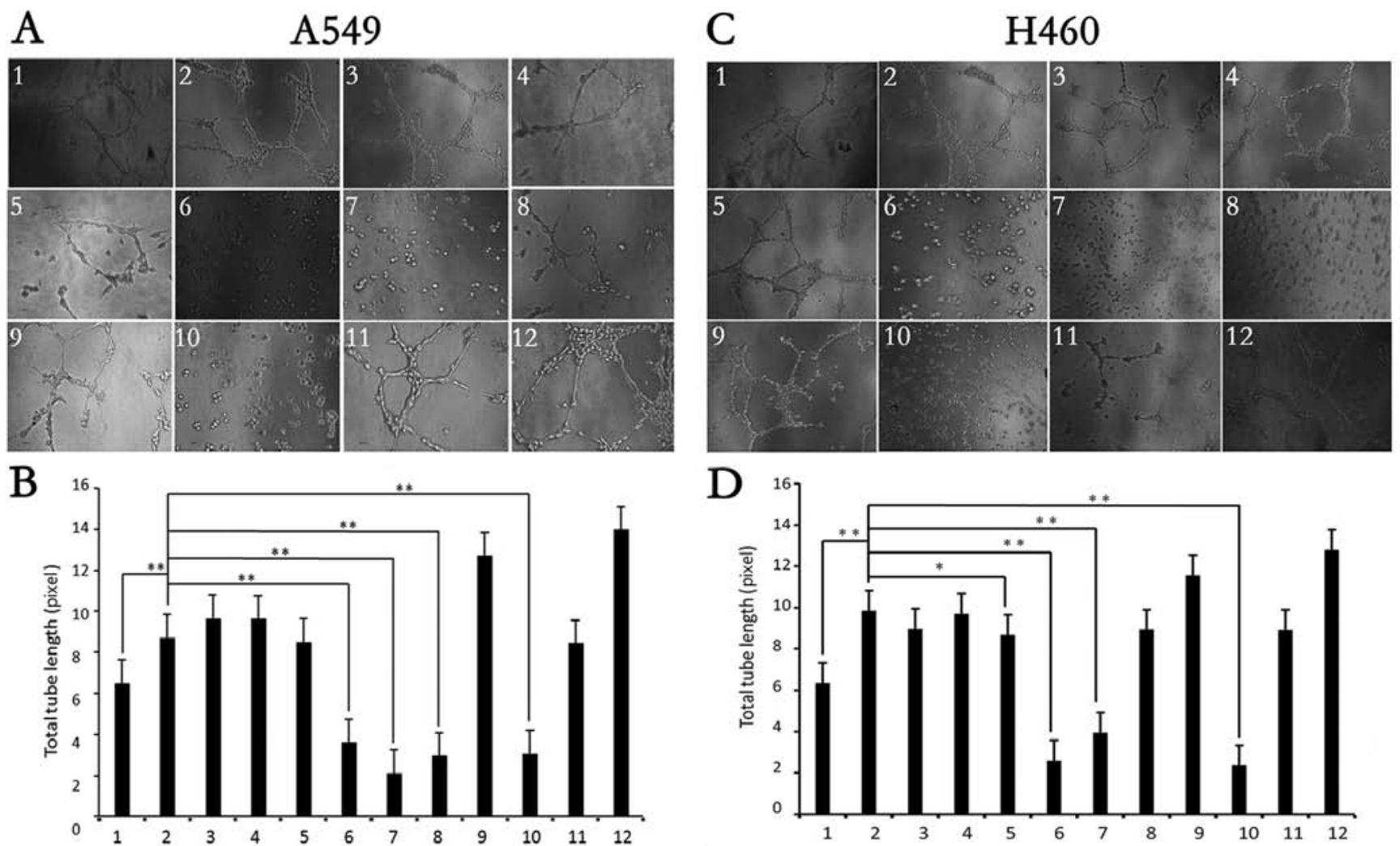

Figure 6. Effects of endophytic fungal fermentation on HPV-16 E7-stimulated lung cancer angiogenesis in vitro. HUVECs were incubated at $37^{\circ} \mathrm{C}$ for $6-8 \mathrm{~h}$ in the conditioned media derived from HPV-16 E7-transfected A549 or NCI-H460 cells treated with different culture broths of endophytic fungi (zj-2, zj-9, zj-12, $\mathrm{zj}-14, \mathrm{zj}-17, \mathrm{zj}-23, \mathrm{zj}-25, \mathrm{zj}-36, \mathrm{zj}-67$ and zj-70). (A and C) Tube formation was observed under a phase-contrast microscope (magnification, $\mathrm{x} 200$ ). (B and D) The total tube length in three random view-fields/well was determined using Scion image software, and the average value was calculated. Lane 1 , empty vector transfection control; lane 2, HPV-16 E7 transfection control (abbreviation, E7); lane 3, zj-2 + E7; lane 4, zj-9 + E7; lane 5, zj-12 + E7; lane 6, zj-14 + E7; lane 7, zj-17 + E7; lane 8, zj-23 + E7; lane 9, zj-25 + E7; lane 10, zj-36 + E7; lane 11, zj-67 + E7; lane 12. zj-70 + E7. All data are expressed as mean \pm SD of three independent experiments; ${ }^{*} \mathrm{P}<0.05,{ }^{* *} \mathrm{P}<0.01$.

activity via inhibition of capillary morphogenesis gene protein 2 (CMG2) (37). Particularly, toluquinol, isolated from marine fungus secondary metabolites, was also demonstrated to inhibit angiogenesis both in vitro and in vivo partly by the suppression of VEGF and FGF-induced Akt activation (38). In the present study, we established an HPV-16 E7 oncoproteininduced lung cancer angiogenic model according to our previous findings $(26,27)$, and further observed the effects of endophytic fungi which have high inhibitory effect on angiogenesis in vitro. We found that $\mathrm{zj}-14, \mathrm{zj}-17$ and $\mathrm{zj}-36$ endophytic fungi significantly inhibited lung cancer angiogenesis in vitro. Notably, strain zj-9 was found to have the strongest inhibitory effect on the growth of lung cancer cells, but it did not exhibit anti-angiogenic activity, indicating that strain $z j-9$ may have cell cytotoxicity but not anti-angiogenic activity, and this issue warrants further study.

\section{Acknowledgements}

The present study was supported by grants from the National Natural Science Foundation of China (no. 81372511) (to X.T.), the Guangdong Provincial Department of Science and Technology (Research and Development of Industrial Technology in Guangdong Province) (no. 2013B031100002) (to X.T.), and the Zhanjiang Municipal Governmental Specific
Financial Fund Allocated for Competitive Scientific and Technological Projects (no. 2012C0303-56) (to X.T.).

\section{References}

1. Campos FF, Sales Junior PA, Romanha AJ, Araújo MS, Siqueira EP, Resende JM, Alves TM, Martins-Filho OA, Santos VL, Rosa CA, et al: Bioactive endophytic fungi isolated from Caesalpinia echinata Lam. (Brazilwood) and identification of beauvericin as a trypanocidal metabolite from Fusarium sp. Mem Inst Oswaldo Cruz 110: 65-74, 2015.

2. Sun ZH, Liang FL, Chen YC, Liu HX, Li HH and Zhang WM: Two new xyloketals from the endophytic fungus Endomelanconiopsis endophytica derived from medicinal plant Ficus hirta. J Asian Nat Prod Res 18: 1036-1041, 2016.

3. Sun W, Chen X, Tong Q, Zhu H, He Y, Lei L, Xue Y, Yao G, Luo Z, Wang J, et al: Novel small molecule $11 \beta$-HSD1 inhibitor from the endophytic fungus Penicillium commune. Sci Rep 6: 26418, 2016.

4. Xu DB, Ye WW, Han Y, Deng ZX and Hong K: Natural products from mangrove actinomycetes. Mar Drugs 12: 2590-2613, 2014.

5. Debbab A, Aly AH,Lin WH and Proksch P: Bioactive compounds from marine bacteria and fungi. Microb Biotechnol 3: 544-563, 2010.

6. Wang J, Ding W, Wang R, Du Y, Liu H, Kong X and Li C: Identification and bioactivity of compounds from the mangrove endophytic fungus Alternaria sp. Mar Drugs 13: 4492-4504, 2015.

7. Cui H, Liu Y, Nie Y, Liu Z, Chen S, Zhang Z, Lu Y, He L, Huang $X$ and She $Z$ : Polyketides from the mangrove-derived endophytic fungus Nectria sp. HN001 and their $\alpha$-glucosidase inhibitory activity. Mar Drugs 14: pii: E86, 2016. 
8. Ding B, Wang Z, Huang X, Liu Y, Chen W and She Z: Bioactive $\alpha$-pyrone meroterpenoids from mangrove endophytic fungus Penicillium sp. Nat Prod Res: Apr 11, 1-8, 2016 (Epub ahead of print).

9. Liu Y, Chen S, Liu Z, Lu Y, Xia G, Liu H, He L and She Z: Bioactive metabolites from mangrove endophytic fungus Aspergillus sp. 16-5B. Mar Drugs 13: 3091-3102, 2015.

10. Bai ZQ, Lin X, Wang Y, Wang J, Zhou X, Yang B, Liu J, Yang X, Wang Y and Liu Y: New phenyl derivatives from endophytic fungus Aspergillus flavipes AIL8 derived of mangrove plant Acanthus ilicifolius. Fitoterapia 95: 194-202, 2014

11. Zhou XM, Zheng CJ, Chen GY, Song XP, Han CR, Tang XZ, Liu RJ and Ren LL: Two new stemphol sulfates from the mangrove endophytic fungus Stemphylium sp. 33231.J Antibiot 68: 501-503, 2015.

12. Meng LH, Zhang P, Li XM and Wang BG: Penicibrocazines A-E five new sulfide diketopiperazines from the marine-derived endophytic fungus Penicillium brocae. Mar Drugs 13: 276-287, 2015.

13. Lv F, Daletos G, Lin W and Proksch P: Two new cyclic depsipeptides from the endophytic fungus Fusarium sp. Nat Prod Commun 10: 1667-1670,2015.

14. Wang M, Zhang W, Xu W, Shen Y and Du L: Optimization of genome shuffling for high-yield production of the antitumor deacetylmycoepoxydiene in an endophytic fungus of mangrove plants. Appl Microbiol Biotechnol 100: 7491-7498, 2016.

15. Deng C, Huang C, Wu Q, Pang J and Lin Y: A new sesquiterpene from the mangrove endophytic fungus Aspergillus terreus (No. GX7-3B). Nat Prod Res 27: 1882-1887, 2013.

16. Chokpaiboon S, Choodej S, Boonyuen N, Teerawatananond T and Pudhom K: Highly oxygenated chromones from mangrove-derived endophytic fungus Rhytidhysteron rufulum. Phytochemistry 122: 172-177, 2016.

17. Li J, Xue Y, Yuan J, Lu Y, Zhu X, Lin Y and Liu L: Lasiodiplodins from mangrove endophytic fungus Lasiodiplodia sp. 318. Nat Prod Res 30: 755-760, 2016.

18. Wang J, Cox DG, Ding W, Huang G, Lin Y and Li C: Three new resveratrol derivatives from the mangrove endophytic fungus Alternaria sp. Mar Drugs 12: 2840-2850, 2014

19. Huang L, Zhang T, Li S, Duan J, Ye F, Li H, She Z, Gao G and Yang X: Anthraquinone G503 induces apoptosis in gastric cancer cells through the mitochondrial pathway. PLoS One 9: e108286, 2014.

20. Chen WL, Turlova E, Sun CL, Kim JS, Huang S, Zhong X, Guan YY, Wang GL, Rutka JT, Feng ZP, et al: Xyloketal B suppresses glioblastoma cell proliferation and migration in vitro through inhibiting TRPM7-regulated PI3K/Akt and MEK/ERK signaling pathways. Mar Drugs 13: 2505-2525, 2015.

21. Wang X, Tan T, Mao ZG, Lei N, Wang ZM, Hu B, Chen ZY, She ZG, Zhu YH and Wang HJ: The marine metabolite SZ-685C induces apoptosis in primary human nonfunctioning pituitary adenoma cells by inhibition of the Akt pathway in vitro. Mar Drugs 13: 1569-1580, 2015.

22. Xie G, Zhu X, Li Q, Gu M, He Z, Wu J, Li J, Lin Y, Li M, She Z, et al: $\mathrm{SZ}-685 \mathrm{C}$, a marine anthraquinone, is a potent inducer of apoptosis with anticancer activity by suppression of the Akt/FOXO pathway. Br J Pharmacol 159: 689-697, 2010

23. Wang D, Wang S, Liu Q, Wang M, Wang C and Yang H: SZ-685C exhibits potent anticancer activity in both radiosensitive and radioresistant NPC cells through the miR-205-PTEN-Akt pathway. Oncol Rep 29: 2341-2347, 2013.

24. Zhu X, He Z, Wu J, Yuan J, Wen W, Hu Y, Jiang Y, Lin C Zhang Q, Lin $\mathrm{M}$, et al: A marine anthraquinone SZ-685C overrides adriamycin-resistance in breast cancer cells through suppressing Akt signaling. Mar Drugs 10: 694-711, 2012.
25. Folkman J: Role of angiogenesis in tumor growth and metastasis. Semin Oncol 29 (Suppl 16): S15-S18, 2002.

26. Li G, He L, Zhang E, Shi J, Zhang Q, Le AD, Zhou K and Tang X: Overexpression of human papillomavirus (HPV) type 16 oncoproteins promotes angiogenesis via enhancing HIF-1 $\alpha$ and VEGF expression in non-small cell lung cancer cells. Cancer Lett 311: 160-170, 2011.

27. Zhang E, Feng X, Liu F, Zhang P, Liang J and Tang X: Roles of PI3K/Akt and c-Jun signaling pathways in human papillomavirus type 16 oncoprotein-induced HIF-1 $\alpha$, VEGF, and IL-8 expression and in vitro angiogenesis in non-small cell lung cancer cells. PLoS One 9: e103440, 2014.

28. Tao YW, Lin YC, She Z-G, Lin MT, Chen PX and Zhang JY: Anticancer activity and mechanism investigation of beauvericin isolated from secondary metabolites of the mangrove endophytic fungi. Anticancer Agents Med Chem 15: 258-266, 2015.

29. Shi J, Liu F, Zhang W, Liu X, Lin B and Tang X: Epigallocatechin-3-gallate inhibits nicotine-induced migration and invasion by the suppression of angiogenesis and epithelial-mesenchymal transition in non-small cell lung cancer cells. Oncol Rep 33: 2972-2980, 2015.

30. He L, Zhang E, Shi J, Li X, Zhou K, Zhang Q, Le AD and Tang X: (-)-Epigallocatechin-3-gallate inhibits human papillomavirus (HPV)-16 oncoprotein-induced angiogenesis in non-small cell lung cancer cells by targeting HIF-1 $\alpha$. Cancer Chemother Pharmacol 71: 713-725, 2013.

31. Lee J, Yi JM, Kim H, Lee YJ, Park JS, Bang OS and Kim NS Cytochalasin $\mathrm{H}$, an active anti-angiogenic constituent of the ethanol extract of Gleditsia sinensis thorns. Biol Pharm Bull 37: 6-12, 2014.

32. Lee SR, Park JY, Yu JS, Lee SO, Ryu JY, Choi SZ, Kang KS, Yamabe $\mathrm{N}$ and Kim KH: Odisolane, a novel oxolane derivative, and antiangiogenic constituents from the fruits of mulberry (Morus alba L.). J Agric Food Chem 64: 3804-3809, 2016.

33. Park JY, Shin MS, Kim SN, Kim HY, Kim KH, Shin KS and Kang KS: Polysaccharides from Korean Citrus hallabong peels inhibit angiogenesis and breast cancer cell migration. Int J Biol Macromol 85: 522-529, 2016.

34. Goey AK, Chau CH, Sissung TM, Cook KM, Venzon DJ, Castro A, Ransom TR, Henrich CJ, McKee TC, McMahon JB et al: Screening and biological effects of marine pyrroloiminoquinone alkaloids: Potential inhibitors of the HIF-1 $\alpha / \mathrm{p} 300$ interaction. J Nat Prod 79: 1267-1275, 2016.

35. Baharara J, Amini E and Mousavi M: The anti-proliferative and anti-angiogenic effect of the methanol extract from brittle star. Rep Biochem Mol Biol 3: 68-75, 2015.

36. Pompeng P, Sommit D, Sriubolmas N, Ngamrojanavanich N, Matsubara K and Pudhom K: Antiangiogenetic effects of anthranoids from Alternaria sp., an endophytic fungus in a Thai medicinal plant Erythrina variegata. Phytomedicine 20: 918-922, 2013.

37. Cao S, Cryan L, Habeshian KA, Murillo C, Tamayo-Castillo G, Rogers MS and Clardy J: Phenolic compounds as antiangiogenic CMG2 inhibitors from Costa Rican endophytic fungi. Bioorg Med Chem Lett 22: 5885-5888, 2012.

38. García-Caballero M, Marí-Beffa M, Cañedo L, Medina MÁ and Quesada AR: Toluquinol, a marine fungus metabolite, is a new angiosuppresor that interferes with the Akt pathway. Biochem Pharmacol 85: 1727-1740, 2013. 